Derecho \& Realidad

Vol.14 - Núm. 27• Enero - Junio de 2016

Págs. 43-60·ISSN:1692-3936

\title{
Inadecuado uso de la figura de la conciliación en lo contencioso administrativo por parte del servidor público: competencias en su deber $y$ responsabilidad
}

\author{
Inappropriate use of the conciliation in \\ the action under administrative law by the \\ public servant: competence in his duty and \\ responsibility
}

Víctor Diomedes Martínez Silva*

\section{Resumen}

La figura de la conciliación es una herramienta que históricamente ha sido utilizada para arreglar discrepancias entre los seres humanos; asi, se constituye en un mecanismo de solución de conflictos. Por ello, el derecho la aborda como una alternativa eficaz y efectiva mediante la cual se acerca la justicia a los ciudadanos y permite que el sistema judicial se ocupe en asuntos de mayor importancia. 
En el derecho administrativo colombiano la conciliación es un instrumento reciente que busca mejorar la relación con el Estado; representa un mecanismo de descongestión desde el punto de vista jurídico, que ahorra valiosos recursos económicos, en especial cuando es el ciudadano quien cede a las fórmulas presentadas por la administración pública.

Ahora bien, la conciliación puede ser extrajudicial y judicial. La primera se realiza antes o por fuera de un proceso; y la segunda, dentro de un proceso judicial. La conciliación extrajudicial solo tiene lugar ante el agente del Ministerio Público, cuando no procede la vía gubernativa o cuando esta estuviere agotada.

\section{Palabras clave}

Conciliación, contencioso administrativo, mecanismo alternativo, acta de conciliación, medios de control, requisito de procedibilidad, equilibrio mínimo.

\section{Abstract}

Conciliation is a tool that historically has been used to fix disagreements among human beings; thus, it becomes an appropriate mechanism to solve conflicts. For that reason, law uses it as an effective alternative whereby justice approaches to citizens and allows judicial system to take care of more important issues.

In tha Colombian administrative law, conciliation is a recent instrument that aims to improve the relationships with the State; it represents a good way of expediting, from the legal point of view, which saves valuable funds (economic resources), especially when citizens are those who yield to the formulas offered by public administration.

Now, conciliation can be extrajudicial and judicial. The first one is carried out before or extraprocedural; the second one is intraprocedural. Extrajudicial conciliation just takes place at the the agent of the Office of Public Prosecutor when it does not proceed the Administrative Recorse or when it is exhausted.

\section{Keywords}

Conciliation, action under administrative law, alternative mechanism, record of conciliation, means of control, procedure, minimum balance. 


\section{Introducción}

La conciliación extrajudicial en derecho administrativo colombiano despierta suspicacias y temores entre los funcionarios públicos por las implicaciones posteriores que esta pueda tener en posibles investigaciones de carácter disciplinario y en posibles acciones de repetición que puedan ser lesivas para su patrimonio.

En el presente artículo se destacan unas variables del inadecuado uso de esta figura por parte del servidor público, como es, no ser correcto en las conciliaciones, por no conciliar como se debe, no conciliar en su debida oportunidad, conciliar ultra petita, temor a la acción de repetición o al llamamiento en garantía, corrupción administrativa (amiguismo, clientelismo, politiquería), bien sea por el dolo o culpa grave del agente. A la vez, se pretende concientizar sobre qué es la conciliación, cuáles son sus beneficios para el erario, su desarrollo y su efecto en Colombia y llamar también la atención sobre la necesidad de formar excelentes abogados conciliadores, pues de su preparación, conocimiento y habilidades depende la posibilidad de llegar a un acuerdo rápido, justo y equitativo entre las partes en beneficio del erario.

Finalmente, hay que resaltar la importancia de la conciliación como mecanismo alternativo de solución de conflictos para todos los colombianos sin excepción. Ojalá la conciliación se extienda a otras esferas de la vida colombiana, acompañada de una persistente e integral tarea educativa, para ir generando en el país una verdadera cultura conciliadora que nos ahorre tiempo y esfuerzo, buscando siempre la meta suprema de superar conflictos mediante acuerdos justos, equilibrados y provechosos para todos.

\section{Problema jurídico}

Se plantea en los siguientes términos: ¿Cuáles y qué tipo de consecuencias produce el inadecuado ejercicio de las competencias del funcionario encargado de la conciliación administrativa y qué soluciones se pueden proponer al respecto?

Para resolverlo es imperioso efectuar un análisis de la conciliación desde el punto de vista jurídico y de la cual se derivan consecuencias económicas. Así las cosas, consiste en establecer cuáles han sido las causas por las que el servidor público utiliza la figura de la conciliación de una manera anacrónica, a sabiendas de que esta institución ayuda a descongestionar despachos judiciales y evita fallos exorbitantes en contra de la nación que afectan el erario. 
Este cuestionamiento surge de la inquietud que dejan los conceptos dados por las altas cortes a lo largo de su historia, que incluso en ocasiones confunden estas características.

Un gran problema de nuestro ordenamiento jurídico se encuentra en la congestión de la administración de justicia, el inadecuado uso de la figura de la conciliación que hacen los servidores públicos al no aplicarla en su momento oportuno por la corrupción administrativa hace que exista un detrimento patrimonial del Estado. La institución de la conciliación extrajudicial en el campo de lo contencioso administrativo permite, en gran medida, la descongestión de los despachos judiciales y el ahorro de grandes cantidades de dineros del erario. Con este artículo se pretende exponer cuáles son los obstáculos por los cuales los servidores públicos no emplean de manera expedita esta figura, a sabiendas de que es un mecanismo de resolución de conflictos que ayuda a minimizar las deudas del Estado, cuando es condenado por el dolo o culpa de sus agentes. Este mecanismo ayuda a contribuir a que la justicia sea ágil, pronta, efectiva y eficaz que, en última instancia, es lo buscado por el particular, es decir, que le solucionen sus controversias sin esperar una decisión judicial de un tribunal de cierre.

Con este artículo se pretende crear un hábito obligacional de utilizar esta herramienta tanto para los particulares, los servidores públicos, litigantes y operadores jurídicos, quienes, por la corrupción administrativa que existe en nuestro país, por su falta de información y conocimiento, prefieren dilatar y dejar esos acuerdos conciliatorios a la siguiente administración, debido al miedo a involucrarse en acciones de repetición, fiscal y disciplinariamente, es por ello que no concilian y, de paso, generan grandes perjuicios para las arcas de la nación.

De otra parte, también se pretende especificar que si el Comité o el servidor, o ambos, no concilian a tiempo y en el futuro es condenado, se hace imperiosa y justificable la acción de repetición, fiscal y disciplinaria, por cuanto está en juego el tesoro de la nación. Se han de proponer, en consecuencia, mecanismos que permitan la recuperación de los dineros públicos que salieron de las arcas del Estado como consecuencia de una conducta atípica de sus funcionarios.

Con lo expuesto en este apartado se muestra cuán importante resulta extinguir los fenómenos que obstaculizan la figura de la conciliación. Vale mencionar, para el efecto, no ser correcto en las conciliaciones, no conciliar como se debe, o conciliar ultra petita, el clientelismo, el amiguismo, la politiquería, la corrupción administrativa, la discrecionalidad de los comités de conciliación por cuanto ellos no tienen un control de legalidad que los vigile y el aval para presentar fórmulas de arreglo, los miembros del comité no tienen los conocimientos idóneos para 
estudiar y presentar propuestas acordes con las pretensiones de los particulares $\mathrm{y}$, en muchos casos, presentan fórmulas por debajo de un $50 \%$. Ahora bien, otro ingrediente importante son los miembros de ese Comité, a quienes no les interesa conciliar inmediatamente; al contrario, dejan pasar el tiempo para que la siguiente administración tome decisiones y así evitar la acción de repetición, fiscal y disciplinariamente, pese a ser un imperativo constitucional el iniciar tales acciones y, de paso, cumplir con los objetivos plasmados en la Ley 678 de 2001.

Esta investigación aventura la hipótesis de que mientras el Estado colombiano no afine sus instrumentos de control y vigilancia para luchar frontalmente contra la corrupción y no destine los recursos suficientes para el fortalecimiento de esta figura, se seguirá presentando un detrimento importante y permanente del tesoro público, originado en distintos fenómenos, entre otros, los errores y fallas de los funcionarios, las imperfecciones persistentes de la acción de repetición y la carencia de personas y recursos para atender la inmensa avalancha de procesos que infartan y entorpecen el trabajo de los distintos estrados judiciales. Dentro de este contexto, se hace necesario identificar las variables por las cuales la conciliación no ha respondido a las expectativas que se tenían de esta figura.

Aunque se reconoce su importancia y su vigencia como mecanismo alternativo de solución de conflictos en Colombia, la conciliación extrajudicial en lo contencioso administrativo no ha dejado de estar en el centro de la controversia jurídica por sus cuestionables resultados como instrumento efectivo de solución de conflictos y como metodología alternativa de descongestión de los despachos judiciales. Los análisis, los hechos y las cifras están descritos en capítulos precedentes y puede argumentarse que ha faltado más profundidad y persistencia en la implementación de esta importante institución jurídica en su debida oportunidad, por escasa ilustración, capacitación, socialización de sus características, beneficios para el erario, y sus alcances por parte de los funcionarios públicos, rompiendo el paradigma de la acción de repetición, sanciones disciplinarias e incluso penales, para así lograr que la conciliación no sea una figura reservada, escondida y casi clandestina que despierta temor y desconfianza y a la cual no se le concede la misma validez que a un proceso formal.

A pesar de las bondades y beneficios del mecanismo, no dejan de presentarse tropiezos, equivocaciones y desacuerdos en su aplicación, en parte por la complejidad y amplitud de las normas que lo rigen y por el desconocimiento casi generalizado de los funcionarios implicados en su aplicación, debido a muchos factores, como son la carencia de capacitación por parte del Gobierno y de los organismos que deberían estar al frente de este proceso, dificultades para la comprensión de las normas que lo rigen y claro está, también en algunas ocasiones, por la mala fe de 
algunos funcionarios que por el dolo o culpa grave no utilizan la figura de una manera adecuada.

Teniendo en cuenta las anteriores observaciones, en el presente artículo se hacen algunas consideraciones acerca de la posible responsabilidad de los funcionarios por no realizar bien las conciliaciones, se tienen en cuenta algunas directrices y lineamientos de los organismos de control como la Procuraduría General de la Nación y la Contraloría General de la República. Es bien sabido que algunos funcionarios no son correctos en las conciliaciones, en no conciliar a tiempo, no concilian como se debe o concilian por encima de lo que se debe, siendo desviaciones nocivas y peligrosas en el desarrollo del mecanismo de la conciliación, que ameritan la revisión doctrinaria de las normas y la aplicación estricta de la ley, como se propone en este artículo.

Los vicios e imperfecciones en el desarrollo de la conciliación extrajudicial en lo contencioso administrativo están generando un detrimento importante del patrimonio del Estado, por causa del pago de indemnizaciones mayores, intereses de más, requiriéndose con urgencia indagar por qué no está siendo efectivo el mecanismo. Se permite reflexionar sobre la transparencia, la buena fe, la probidad, el adecuado ejercicio de la función pública, el deber, lealtad de los agentes del Estado, la eficiencia y la moralidad administrativa, que son principios de la función pública consagrados en el Artículo 209 de la Carta Política y que han sido objeto de pronunciamientos jurisprudenciales por las altas cortes, en especial en lo concerniente a la responsabilidad de los funcionarios públicos por sus actuaciones inapropiadas o dolosas durante la realización de las conciliaciones. La conducta de estos servidores del Estado está sujeta a normas establecidas que señalan con suficiente claridad cuáles son sus deberes y derechos y establece también cuáles son las consecuencias de sus acciones u omisiones no ajustadas a derecho, como es factible observar en las siguientes consideraciones.

En efecto, aun cuando el pago constituye la concretización del daño sufrido por la entidad, son los hechos de la administración, materializados en la conducta o actuación de manera dolosa o gravemente culposa de uno de los funcionarios al servicio del Estado, los que causaron el perjuicio al particular y por ende son los mismos que originan la responsabilidad personal del funcionario frente a la administración. De acuerdo con la Constitución Política y la ley, para que prospere la responsabilidad del funcionario se exige que el perjuicio de la entidad sea concretado en el pago de la suma ordenada o conciliada.

Por otra parte, los servidores públicos son responsables no solo por infringir la Constitución y las leyes, sino también por extralimitación u omisión en el ejercicio de 
sus funciones, sin que les sea dable oponer el cumplimiento de un mandato superior para eximirse de responsabilidad, así se desprende lo preceptuado por los artículos 6, 91 y 124 de la Constitución Política, cuando se cometa una infracción manifiesta de un precepto constitucional, que cause daño o detrimento a una persona. Estas son presunciones iuris tantum y, por tanto, puede probarse lo contrario, de hecho, aunque el dolo y la culpa grave aparezcan acreditadas en un proceso precedente, en el proceso de repetición el agente estatal puede demostrar la inexistencia del factor subjetivo que lo hace sujeto pasivo de la repetición.

Lo anterior implica que no hay responsabilidad subjetiva del servidor público de manera directa con la víctima derivada de su acción u omisión, sino que el sujeto de la responsabilidad es el Estado, es una responsabilidad de índole institucional que comprende no solo el ejercicio de la función administrativa, sino todas las actuaciones de todas las autoridades públicas, sin importar la rama del poder público a que pertenezcan. De igual manera, la anterior acepción se aplica cuando se trate de otros órganos autónomos e independientes creados por la Constitución o la ley para el cumplimiento de las demás funciones a cargo del Estado (Ayala, 2006, p. 287).

La calidad de servidor y funcionario público conlleva la decisión de asumir unas claras y delimitadas responsabilidades, e implica también tener conciencia de que se es sujeto de derechos, de no extralimitarse en sus funciones y ser protector del erario. El ejercicio de la función pública supone el respeto de unos principios éticos como son la buena fe, la moral pública, la transparencia, que deben ser tenidos en cuenta por todo servidor público o por los particulares que ejecutan funciones públicas, a la hora de cumplir las funciones que les han sido confiadas. A pesar de esto, la sujeción a dichos principios no implica que el proceso de responsabilidad disciplinaria sea adelantado teniendo presente conceptos morales o subjetivos, por el contrario, para que se pueda hablar de esta clase de responsabilidad es necesario que el funcionario o particular que ejerce funciones públicas infrinja por acción $u$ omisión la ley y los reglamentos que guían su actuar.

En cuanto a los deberes como funcionarios, podría decirse que la responsabilidad es la capacidad de conocer y aceptar las consecuencias de sus actos, exigida únicamente desde la libertad y la conciencia de una obligación, y para que exista así el autor de un acto $u$ omisión que afecta a terceros, debe haber actuado libremente y con pleno conocimiento. Es por ello que se reprocha la actuación de los funcionarios encargados de adelantar una conciliación, que no la ejercitan por el miedo de la acción de repetición o porque lo llamen en garantía, o debido al amiguismo, el clientelismo y hasta la misma politiquería, convirtiéndose en corrupción administrativa y un detrimento al patrimonio del Estado. 
Ahora bien, el Estado colombiano viene siendo condenado a pagar cuantiosas sumas de dinero en virtud de los daños antijurídicos ocasionado por sus agentes por la acción u omisión y sin que exista una eficaz acción de repetición para recuperar las sumas pagadas, e igualmente por las normas disciplinarias que son escuetas y a la vez las sanciones son ínfimas.

Los servidores públicos de manera indirecta son guardianes del fisco de la nación, deben actuar con probidad, rectitud, cumpliendo con sus deberes y funciones, porque de lo contrario estarían cometiendo faltas y generando responsabilidad que origina grandes perjuicios en contra del erario. Si bien es cierto en nuestra legislación no se encuentra tipificada la conducta por el inadecuado uso de la figura de la conciliación, dicha falta debe ser sancionada a título de dolo, por cuanto el funcionario no da la aplicación adecuada a la figura de la conciliación extrajudicial.

Existen varias clases de responsabilidad, dependiendo del cargo u oficio de la persona, como lo son la responsabilidad penal, civil, fiscal, administrativa y disciplinaria.

Empezando por la civil, encontramos que la responsabilidad del particular o funcionario público se clasifica ante el Estado y el particular por daños causados debido a su actuación y por incumplimiento, omisión o extralimitación de funciones a su cargo. En cambio, aquellos actos de un funcionario que no son delitos pero perturban el normal cumplimiento de sus funciones, pertenecen a la responsabilidad disciplinaria, es decir, aquellas acciones u omisiones que perjudiquen el desempeño de un ente conllevan una sanción disciplinaria de acuerdo con el marco jurídico de control estipulado por la Ley 734 de 2002, en cuyos Artículos 42, 43 y 44 recae la responsabilidad por sus actuaciones a los servidores públicos o particulares que cumplan funciones prácticas o de interventoría en contratos estatales.

Por su parte, la responsabilidad fiscal es aquella relacionada con la administración de los recursos públicos y que se deriva de la gestión realizada por funcionarios o particulares que manejan recursos del Estado y que en Colombia es determinada por la Contraloría General de la República, que busca en el proceso obtener una declaración jurídica en la cual se concluya que un determinado servidor público o particular debe asumir las consecuencias de sus actuaciones irregulares y reparar el daño causado. Se observan aquí las dos clases de responsabilidad fiscal: sancionatoria y resarcitoria. La primera sanciona al responsable del mal manejo de los recursos públicos y la segunda busca que este reintegre el daño causado al patrimonio 
público. La responsabilidad patrimonial de los funcionarios públicos es de carácter reparativo mas no sancionatorio, así lo manifiesta la Corte Constitucional ${ }^{1}$.

En cuanto a la responsabilidad administrativa que surge de la comisión de una contravención de un cargo directivo en una organización pública derivada, esta existe por todo perjuicio causado a terceros por la acción u omisión de un acto administrativo. La responsabilidad administrativa es propia de los cargos directivos con cuyas decisiones se causan perjuicios que tienen implicaciones penales o civiles. Cuando estas implicaciones son consecuencia de acciones intencionales o actos imprudentes de servidores públicos, que conducen a condenas económicas en contra de entidades gubernamentales producto de demandas contra el Estado, el funcionario que bajo una conducta dolosa o gravemente culposa actuó imprudentemente será sometido a una acción de repetición por parte del Estado, para que con su patrimonio reintegre a la nación, ya que cada vez que una entidad oficial es condenada a pagar indemnizaciones lo hace con dineros oficiales.

Volviendo a la acción de repetición y su relación con la conciliación, es factible encontrar tres puntos claves emitidos por la Agencia Nacional de Defensa Jurídica del Estado: i) el requisito de procedibilidad atinente a la conciliación prejudicial no es aplicable a la acción de repetición; ii) la acción de repetición procede también cuando el detrimento patrimonial del Estado es generado por la conducta dolosa o gravemente culposa de uno de sus agentes, sea consecuencia de una conciliación u otra solución de conflicto permitido por la ley; iii) la acción de repetición no se extingue cuando en un proceso judicial se concilie respecto de la pretensión patrimonial ejercida contra el Estado.

Reglamentado por el Parágrafo $4^{\circ}$ del Artículo $2^{\circ}$ del Decreto 1716 de 2009, hizo extensivo el requisito de procedibilidad de la conciliación extrajudicial a la acción de repetición. El Consejo de Estado ha indicado que no es posible exigir la conciliación prejudicial, ya que el mencionado artículo señaló taxativamente las sanciones en las que se aplica el requisito de procedibilidad, a saber: la acción de nulidad y restablecimiento de derecho, la reparación directa y la de controversias contractuales, sin consagrar la acción de repetición. Esta tesis está respaldada por la Corte Constitucional en la Sentencia C-314 de 2002, donde se prescribe que el Parágrafo $1^{\circ}$ del Artículo 37 de la Ley 640 de 2001 no vulnera el principio de igualdad al excluir del requisito de procedibilidad de la conciliación prejudicial a

1 La Corte Constitucional (sentencia C-309 de 2000. M.P. Antonio Barrera Carbonell) señala: "Esta responsabilidad no tiene carácter sancionatorio, ni penal, ni administrativo, pues la declaración de responsabilidad tiene una finalidad meramente resarcitoria...". 
la acción de repetición, pues, resulta acorde con los fines constitucionales al hacer menor la carga procesal para el Estado.

En relación también con lo anterior, la Corte Constitucional señaló que es posible ejercerla cuando el reconocimiento indemnizatorio provenga de una conciliación, pues si no lo fuera sería inconstitucional; así mismo, la Corte ha sostenido que si se llegara a un acuerdo conciliatorio dentro de un proceso de responsabilidad estatal relacionado con la pretensión patrimonial que se ejerce contra el Estado, no se extingue en este caso la acción de repetición en contra del servidor público que actuó con dolo o culpa grave, entonces debe seguirse el proceso para que se resuelva la obligación de llamado en garantía y así reembolsar al Estado las sumas, aunque se haya puesto fin a la pretensión de conciliación.

Igualmente, la buena fe no exime de responsabilidad al funcionario que al asumir un cargo está en la obligación de conocer, mínimamente, las normas que regulan las actividades para su desempeño y que por cualquier razón actúa en contra de ellas. Si fuera así, no tendría sentido el Artículo 6 superior, cuando establece que los servidores públicos son responsables de sus actuaciones, por infringir la Constitución y las leyes y además, por la omisión o extralimitación en el ejercicio de sus funciones.

A su vez, la Corte Constitucional en Sentencia C-1195 de 2001 resaltó las siguientes características específicas de la conciliación extrajudicial en asuntos contenciosos administrativos. En materia contenciosa administrativa, el legislador estableció unas condiciones particulares que reducen la posibilidad de afectación del derecho de acceso a la justicia. En primer lugar, con el fin de proteger la legalidad y los intereses patrimoniales del Estado, la conciliación administrativa debe ser aprobada judicialmente. En segundo lugar, la conciliación administrativa solo puede ser adelantada ante los agentes del Ministerio Público asignados a la jurisdicción contenciosa administrativa. Ello implica una intervención mayor del conciliador con el fin de proteger el interés general, la legalidad del proceso y los derechos fundamentales. Además, el conciliador puede solicitar pruebas adicionales a las presentadas por las partes para la sustentación del acuerdo conciliatorio y si tales pruebas no son aportadas, puede decidir que no se logró el acuerdo. En tercer lugar, la conciliación administrativa impone a los representantes de las entidades públicas no solo la obligación de concurrir a la audiencia de conciliación, sino además la obligación de discutir las propuestas de solución que se hagan, salvo que exista justificación para ello, y de proponer fórmulas de solución. El incumplimiento de estas obligaciones da lugar a sanciones disciplinarias. 
En cuanto a la afectación a los dineros públicos, no se puede pensar que las finanzas estatales se perjudicarán por la conciliación, sino mas bien que por este mecanismo el Estado atenderá cumplida y prontamente sus obligaciones, estableciendo, eso sí, los controles debidos.

Es por ello, que un servidor público al no conciliar en su debida oportunidad y dilatar la audiencia de conciliación está perjudicando al erario, por cuanto cada día que pasa el valor por conciliar va generando intereses que favorecen al demandante y por tal razón debe ser sancionado disciplinaria y fiscalmente haciéndose merecedor de la acción de repetición para devolverle al Estado esa diferencia de dinero que no concilió a tiempo.

De nada sirve tener la figura de la conciliación extrajudicial en materia contencioso administrativa, con el fin de amparar el fisco, si un servidor público por su dolo en su oportunidad no concilió una determinada cifra de dinero y en el futuro el Estado queda obligado a cancelar ese valor pero ya indexado y con intereses a través de un proceso judicial.

La Ley 678 de 2001 regula la acción de repetición, conocida como una herramienta para recuperar esos montos de dinero que el Estado fue condenado a pagar como perjuicios por el dolo de uno de sus agentes; igualmente, esta acción busca el amparo de la moralidad pública y la eficiencia de la función pública con el fin de la defensa del patrimonio estatal.

Con esta investigación se busca crear una abogacía de Estado, concientizar al servidor público de utilizar de manera adecuada y prioritaria la figura de la conciliación y fortalecer más esta acción, con el propósito de recuperar algo del dinero que el Estado ha tenido que pagar por el inadecuado uso de la conciliación extrajudicial por parte de sus agentes; igualmente es necesario fortalecer el régimen disciplinario, la acción de repetición o llamar en garantía al funcionario dentro del proceso en que quedó condenado el Estado.

Con lo anterior, al emplear de manera adecuada la figura de la conciliación en su momento oportuno, el Estado se estaría ahorrando gran parte de su erario, pero para ello se debe inculcar al servidor público que es un deber utilizar a tiempo la conciliación extrajudicial en pro del patrimonio de la nación y dejar a un lado el miedo de la acción de repetición.

El Estado moderno va evolucionando y por consiguiente el poder soberano ha pasado a no asumir sus propias responsabilidades frente a los daños ocasionados a sus asociados en diversas controversias jurídicas, acarreando un daño antijurídico, 
que según la jurisprudencia, es provocado a una persona que no tiene el deber jurídico de soportarlo. Así, la responsabilidad patrimonial del Estado se presenta entonces como un mecanismo de protección de los administrados frente al aumento de la actividad del poder público, el cual puede provocar daños por la conducta dolosa o culposa de los funcionarios públicos. Esa responsabilidad patrimonial se origina por la desidia, la indolencia, la falta de transparencia, eficacia y eficiencia del funcionario público, al no conciliar en su debida oportunidad, por dilatarla, por no conciliar como se debe o conciliar de manera ultra petita.

Ergo, cuando se habla de responsabilidad, el Estado responderá patrimonialmente por los daños que le sean imputables, causados por la acción o la omisión de sus funcionarios por tener una conducta dolosa o gravemente culposa, el cual deberá repetir contra este último. Por lo que surge la obligación del Estado de restablecer su propio patrimonio por medio de la acción de repetición y sancionar disciplinariamente al agente infractor.

El gran problema surge cuando los funcionarios públicos, dentro de un contexto de clientelismo, politiquería, amiguismo, generan la corrupción administrativa, contrariando los postulados de moralidad, transparencia y eficiencia que deben observar, pues es normal que los funcionarios encargados en conciliar no lo hagan a tiempo, dejen para la siguiente administración, dilaten la fecha de audiencia, concilien sin tener soportes fácticos y de derecho, o concilien de manera ultra petita, con el fin de beneficiar a terceros y de evitarse la acción reparativa o el llamamiento en garantía, en detrimento del erario, y además se insolventan.

Más que reformas normativas, lo que se quiere en esta investigación es implementar una nueva forma de administración del Estado, donde se fomenten los valores sociales relacionados con la moral administrativa, transparencia de la función pública, desligando intereses económicos, partidistas y personales de los servidores públicos que tienen a su cargo agotar la conciliación en debida forma en pro del erario.

En lo referente al derecho comparado, en Francia, cuna del derecho administrativo, se ha distinguido entre la responsabilidad derivada de la falla del servicio y la derivada de la culpa personal del agente o servidor público. La jurisprudencia francesa ha sostenido que hay falla del servicio cuando el daño es impersonal y revela a un administrador más o menos sujeto al error y hay culpa personal del agente si la actuación muestra al hombre con sus debilidades, sus pasiones, sus imprudencias (Rodríguez, 2000, p. 415). La responsabilidad será del agente del Estado, debiendo responder este con su patrimonio. 
Actualmente, percibiendo la problemática que está sufriendo el Estado por las numerosas conciliaciones extrajudiciales y la ineficacia de la acción de repetición, se hace imperioso analizar cuáles son las variables por las cuales el servidor público le teme a conciliar, entre ellas tenemos, el miedo de la acción de repetición, el desconocimiento del precedente judicial, la unificación de la jurisprudencia, la falta de profesionalismo, la corrupción administrativa como es, el amiguismo, el clientelismo, la politiquería. Todo lo anterior lleva al funcionario encargado de conciliar a no ser correcto en las conciliaciones, no conciliar como se debe, conciliar ultra petita o dilatar para que la siguiente administración concilie, y aunado a ello la normatividad disciplinaria es escueta y la insolvencia de ese servidor da lugar para que exista detrimento a las finanzas públicas.

En síntesis, en la práctica, todas las anteriores variables han abordado el estudio de lo que he denominado el inadecuado uso de la figura de la conciliación por parte del servidor público y bajo el precepto de que esta institución es la panacea del derecho contencioso administrativo, el funcionario encargado de aplicarla se escuda en conciliar sus errores con conducta dolosa. Las manifestaciones del inadecuado uso de la conciliación son numerosas, ya que es una responsabilidad subjetiva del funcionario el actuar de manera irresponsable, pero quizás todas ellas respondan a un mismo común denominador que es el miedo a la acción de repetición y el detrimento del patrimonio público.

A manera de conclusión analítica, debe afirmarse categóricamente que la conducta de los funcionarios públicos que no realizan bien las conciliaciones, que no son correctos, justos, ni objetivos y que evaden su compromiso causándole graves perjuicios al Estado colombiano, debe ser sometida sin dilación al examen riguroso de los organismos de control, para determinar con exactitud y objetividad cuáles fueron sus responsabilidades y castigar ejemplarmente, por cuanto generó un mayor detrimento al fisco. El problema de la impunidad y del detrimento patrimonial al Estado no surge entonces como consecuencia de la ausencia de normas o de un régimen sancionatorio poco claro, sino de la lentitud y desidia con que se realizan las investigaciones, circunstancias estas que generan posibilidades a la corrupción administrativa (amiguismo, clientelismo, politiquería), y a la extinción de los procesos sin que se haya cumplido su objetivo a cabalidad.

Como lo reconoce la misma Agencia Nacional de Defensa Jurídica del Estado (ANDJE), el caudal normativo implícito en la conciliación extrajudicial en lo contencioso administrativo es bastante profuso y complejo, lo cual debería dar lugar a una reconsideración y simplificación de las normas vigentes para hacerlas más comprensibles y sencillas a las entidades y a los particulares, con lo que seguramente se obtendrían mejores resultados para todos. 
De forma más precisa, resulta indudable que la Ley 734 de 2002 debe ajustarse a un entorno cambiante y en ocasiones mucho más dinámico, en el sentido de prescribir que la conducta inadecuada del servidor público encargado de conciliar sea a título de dolo y con sanciones de separación del servicio, suspensión de las funciones por seis años sin sueldo, como lo es en el sistema jurídico de España ${ }^{2}$, igualmente ejercer de manera expedita la acción de repetición con medidas cautelares previas.

Ahora bien, con esta investigación se pretende romper esos obstáculos del funcionario público por el inadecuado uso de la figura de la conciliación presentando una serie de soluciones, que son:

Poner un límite al monto de las condenas para que estas sean pagables y se pueda recuperar algo del dinero que el Estado ha tenido que pagar. Al respecto se propone una reforma legal en la cual se establezca un monto máximo que represente un porcentaje de la condena, como ya se viene haciendo en algunos países, como Francia.

Tanto los servidores públicos, exservidores, particulares que ejerzan funciones públicas, interventores en contratos estatales y los indígenas que manejen recursos del Estado, deben emplear la figura de la conciliación de manera obligatoria y expedita, sin ninguna dilación, actuando de manera transparente, con honradez, legalidad, probidad, celeridad e imparcialidad.

Así mismo, se deben reformar los Artículos 33 y 34 del Código Disciplinario Único, en el sentido de que el adecuado uso de la figura de la conciliación es un derecho y deber de utilizarla en debido tiempo, esto significa que es imperioso conciliar a la fecha.

Señalar como falta gravísima a título de dolo al servidor público que no concilie en su debida oportunidad, teniendo como sanciones la acción de repetición, la desvinculación del servicio, inhabilitarlo por cinco años para ejercer cargos y contratar con el Estado, investigaciones tanto penal y fiscalmente, y sería novedoso como lo es en España el estatuto básico del empleo público, mientras quede ejecutoriado el fallo sancionatorio el servidor público no recibirá sueldo alguno.

Derogar la conciliación extrajudicial y judicial en la acción de repetición y abrir la brecha en el campo de las medidas cautelares previas, razón por la cual el funcionario público no logre insolventarse, además fortalecer la acción de repetición y el llamamiento de garantía en ser más expedito y sumario el procedimiento.

2 Ley 7 de 2007. Estatuto Básico del Empleo Público. España. 
Con lo anterior, para los cargos de alto nivel o los integrantes del comité de conciliación (o ambos) en el momento de la posesión del cargo deberán adquirir una póliza con el fin de amparar los detrimentos patrimoniales sufridos por el Estado en cabeza de servidores públicos que obstaculicen la nueva y normal realización de la conciliación.

Se encuentra útil que las entidades destinen un rubro anual dentro del presupuesto, para fortalecer la defensa pública y las acciones de repetición. En sentido similar, se propone también ampliar la exigencia o constitución de pólizas de garantía por cinco años para ciertos cargos, con lo cual se pueda proteger el posible detrimento patrimonial.

Se formula otro tipo de acciones para hacer más eficaz la acción de repetición; tal es el caso de extender las consecuencias del fallo condenatorio al ámbito disciplinario, como por ejemplo, que esto se convierta en inhabilidades para el ejercicio de cargos públicos y la contratación estatal. Esto implica por supuesto, realizar las reformas legales del caso, tanto en el Código disciplinario, como en la misma Ley 678 de 2001.

También se propone la modificación de la competencia para conocer de la acción de repetición, en el sentido de que el juez que conoció del proceso de condena al Estado, sea el mismo juez en tramitarla, no como un proceso sino como un incidente, a fin de tener más celeridad y eficiencia para la recuperación del dinero. Esto último, sin embargo, puede ser fruto de una mayor discusión y argumentación, pues se encuentran elementos tanto a favor como en contra, así se hace importante derogar los términos de caducidad y prescripción aboliendo el amiguismo y la politiquería.

\section{Colofón}

El objetivo general del artículo fue determinar si la conciliación se emplea de manera adecuada por parte de los servidores públicos, pues se dedujo que al existir esta figura hay unas variables que utilizan los funcionarios encargados en desarrollarla de manera inadecuada actuando dolosamente al no ser correctos en las conciliaciones, dejando a un lado los principios de eficacia, eficiencia y transparencia, en no conciliar en término, para así evitar la acción de repetición o que la siguiente administración pague lo adeudado.

La prepotencia de los servidores públicos es el enemigo número uno de la conciliación, por sus abusos a través de decisiones ilegales, desviación de poder o demora para que la nueva administración concilie y evitando la acción de repetición, a sabiendas de que la justicia es lenta y costosa. Es necesario erradicar este concepto, 
porque el perjudicado es el Estado al pagar sumas que se hubieran podido pagar en su momento.

Desde la implantación de la conciliación administrativa en los procesos que la requieren, se ha venido utilizando con mayor frecuencia; de 55.665 solicitudes radicadas en el 2012 a 72.888 en el 2013; de estas se llegó a acuerdo un total de 4.606 y 5.463, respectivamente. Lo anterior significa que un número igual de casos ya no tuvieron curso en los juzgados, lográndose el objetivo de descongestionar los despachos y además, que el Estado ahorrara más de un billón de pesos durante este período, alcanzándose las metas económicas. Ante este panorama se debe pensar si se están logrando los fines de la conciliación o si sucede que los servidores públicos están cometiendo más errores afectando el patrimonio de los colombianos. Ello significa que más que flexibilizar la justicia, urgen reformas estructurales en el ejercicio de la función pública.

Para 2013, las pretensiones en conciliaciones prejudiciales eran de \$569'912.678.878; se lograron acuerdos por la suma de \$328’846.056.510. Así el Estado colombiano se ahorró la suma de \$241’066.622.368. Estas cuantías significan que la conciliación se constituye en un mecanismo de solución de conflictos que le sirve al Estado para protegerlo de las altas condenas que le hacen pagar por el dolo o culpa de sus agentes.

En 2014, en los indicadores del sistema de calidad de gestión de la Procuraduría Delegada para la Conciliación Administrativa, para el segundo semestre se lograron 2.660 acuerdos aprobados frente a 677 desaprobados; esto significó para el Estado un ahorro en millones del $261 \%$, lo que refleja que esta figura previa a un proceso judicial ayuda a descongestionar la justicia y a ahorrar las condenas económicas que ha de asumir el Estado por el dolo o culpa grave de sus agentes.

Si bien la figura de la conciliación es un mecanismo de solución de conflictos que, además, ayuda a descongestionar despachos judiciales, las entidades del Estado, al verse demandadas dentro de un proceso contencioso administrativo, la emplean para proteger el erario y en ocasiones, concilian por debajo de un $50 \%$ de la reparación del daño al particular. En la audiencia, ese particular siempre se encuentra en desventaja por la posición dominante del Estado y, en últimas, concilia por el valor que propuso el comité de conciliación, lo cual corrobora el hecho de que el ciudadano siempre se encuentra en desventaja frente al Estado, cuya posición dominante es evidente.

La conciliación extrajudicial administrativa se debe aplicar a todas las acciones de carácter económico sin ninguna limitación, por lo que es necesaria una reforma al Decreto 1716 de 2009, pues al unificar la conciliación como requisito de 
procedibilidad para todas las pretensiones económicas y ser más expedita y ágil para el particular, se beneficia el Estado.

La conciliación extrajudicial administrativa no ha logrado los resultados esperados, por el mal uso que le han dado los servidores públicos y el comité de conciliación, porque no conocen sus beneficios para el erario y por su falta de aplicación a otros asuntos de contenido económico, por temor al llamamiento en garantía o a la acción de repetición.

No es fácil aceptar esta figura como requisito de procedibilidad para asuntos tributarios, laborales y ejecutivos contra los municipios; se puede pensar en un proyecto de ley que regule, además de los medios de control, todas las acciones de contenido económico, un procedimiento más expedito para el particular, ponerlo en práctica, divulgar el beneficio de esta figura a los servidores públicos para evitar acciones de repetición y a través de una correcta aplicación forjar una conciencia conciliadora.

La conciliación extrajudicial como requisito de procedibilidad en lo contencioso administrativo protege los intereses económicos del Estado; se debe fortalecer e instar a los servidores públicos a utilizarla so pena de falta de disciplina grave. Son los mismos funcionarios los encargados de condenar a la nación y poner obstáculos a esta institución al no conciliar y dejar que pase el tiempo condenando al Estado al pago de intereses por mora o indexación monetaria.

La implementación y mejoramiento de los procesos conciliatorios en Colombia requiere del compromiso ético y de la cualificación y actualización de los funcionarios encargados de la conciliación administrativa, esto es la abogacía de Estado, concientizar al servidor público de emplearla a su debido tiempo e igualmente fortalecer sanciones por su inadecuado uso e incluso exigir una póliza a los funcionarios que amparen un presunto detrimento patrimonial.

Falta un compromiso ético real que exija a las diferentes autoridades el cumplimiento de sus funciones y sanciones drásticas contra los servidores públicos que dilaten los términos conciliatorios, pues esto se da por la ausencia de la moralidad pública, transparencia, el clientelismo, el amiguismo, la politiquería, la corrupción administrativa y la falta de conciencia que ponen en juego el erario, y frente a unas leyes disciplinarias y fiscales laxas, se requieren leyes drásticas que disciplinen al funcionario público que concilie a destiempo o no concilie. 


\section{Referencias}

Ayala, J. E. (2006). La responsabilidad de los servidores públicos. Bogotá: Doctrina y Ley.

Barrera, A. M. \& Niño, A. L. (2013). Conciliación en Colombia. Revista Iter ad Veritatem, (11), 117.

Caicedo, L. F. \& Tabares, W. (2013). La figura de la conciliación y sus límites dentro del marco legal de lo contencioso administrativo en Colombia. Cali: Universidad San Buenaventura.

Corte Constitucional colombiana. (2000). Sentencia C-309 de 2000. Magistrado ponente Dr. Antonio Barrera Carbonell.

Corte Constitucional colombiana. (2001). Sentencia C-1195 de 2001. Magistrados ponentes Manuel José Cepeda Espinosa y Marco Gerardo Monroy Cabra.

Legis (2014). Conciliación extrajudicial en asuntos de lo contencioso administrativo. Bogotá: Legis.

Rodríguez, L. (2000). Derecho administrativo general y colombiano. Bogotá: Temis.

Villate, M. A. (2011). Los comités de conciliación como órganos administrativos de análisis de procedencia de las acciones de repetición. Principia Iuris, 2(16), 161. 